\title{
El femicidio en el Ecuador
}

\section{Femicide in Ecuador}

Marcela Anarcaly Zambrano-Orvela uq.cjuridico@uniandes.edu.ec

Universidad Regional Autónoma de Los Andes, Quevedo Ecuador https://orcid.org/0000-0001-5775-0724

Karen Clemencia Triviño-Vera uq.vinculacion@uniandes.edu.ec

Universidad Regional Autónoma de los Andes, Quevedo Ecuador

https://orcid.org/0000-0003-3119-2423

Gilma Nelly Rivera-Segura uq.investigacion@uniandes.edu.ec

Universidad Regional Autónoma de los Andes, Quevedo Ecuador https://orcid.org/0000-0003-1312-5446

Aura Marina Lemos-Espinoza dq.auramle82@uniandes.edu.ec Universidad Regional Autónoma de los Andes, Quevedo Ecuador https://orcid.org/0000-0002-7342-4977

Recepción: 15 de marzo 2021

Revisado: 25 de mayo 2021

Aprobación: 15 de junio 2021

Publicación: 01 de Julio 2021 


\section{Estimado Editor (a):}

El femicidio en la actualidad se ha vuelto un problema más notable y expuesto, y más aun con la llegada de las nuevas tecnologías en donde es inevitable encontrar algún caso en donde una mujer se convirtió en víctima; este hecho es realmente un tema más complejo que no puede ser encasillado como el asesinato de una mujer por diferentes motivos, a su vez también esta palabra ha llegado a ser usada en contextos en los que no deberían, creando así un concepto erróneo de la misma la cual hace más difícil que los casos sean identificables y a su vez se les de la atención que merecen como un problema grave.

En tal sentido Lucas (2014), citado por Proaño Reyes (2019) distingue una diferencia que se debe considerar al respecto plantea:

Es oportuno aclarar que existe una distinción entre femicidio y feminicidio, ya que el primero se presenta como un término homólogo a "homicidio", el cual solo se referiría al asesinato de mujeres, mientras que el segundo, incluiría la variable de impunidad que suele estar detrás de estos crímenes; impunidad que se configura a través de la inacción o desprotección estatal frente a la violencia hecha contra la mujer. (p.94)

Así mismo, es lamentable que en el Ecuador en sus últimos años se han presentado un aumento de casos por femicidio, por ello el Estado ha intentado establecer diferentes tipos y formas en los que se presenta la violencia, pero esto no representa una ayuda a resolver esta problemática. Fácilmente en el Código Orgánico Integral Penal, se demuestra que existe un vacío legal que no protege en su totalidad a la mujer, por otro lado, están los tratados internacionales los cuales no han considerados en la redacción del citado código.

Por lo tanto, el asesinato de mujeres refleja la forma de comportamiento en una sociedad donde los conflictos se resuelven a través de la violencia, y en este caso expresa la desigual relación de poder entre las mujeres en los ámbitos socioeconómicos, político y laborales, una de las situaciones que más se presentan es que la mujer la cual es percibida como menos o es objetivizada realiza una acción que a los ojos de su agresor corresponde a algo como "una falta de respeto" por lo cual el agresor procede a herirla como una forma de desquitarse y sentirse mejor ante 
aquella acción, la situación cambia según el contexto. Al respecto Goyas Cespedes, Zambrano Noles y Zambrano Noles (2018), expresan lo siguiente:

La discriminación de la mujer ha sido institucionalizada a través de los siglos a nivel mundial. Al colocarla en una situación desventajosa en todos los ámbitos de las relaciones sociales, también se le hace blanco de las diversas formas de violencia. (p.131)

En este sentido el tema del asesinato de mujeres se ha vuelto cada vez más evidente en el continente latinoamericano. Sin embargo, esta sigue siendo una realidad que se ha normalizado y se ha llegado al punto de aceptarla. En muchos otros países, la violencia es la causa más frecuente de asesinatos de mujeres. Trabajos recientes han demostrado que el homicidio femenino también ocurre en otros entornos y relaciones con este riesgo fatal, aun cuando cada comportamiento involucra diferentes dinámicas del agresor controlando diferentes mujeres. Esto muestra que las estrategias necesarias para prevenir el asesinato de mujeres también deben ser diferentes en cada caso.

Se destaca lo planteado por la Corporación Promoción de la Mujer (2018):

La violencia femicida es la forma más exacerbada de un continuum de violencias manifestadas en el ámbito familiar o de las relaciones afectivas, sin perjuicio, de que la esfera social o pública también es un espacio de amenaza continua a la vida de las mujeres. Sobre este punto, es importante registrar la información estadística que da cuenta de la violencia que muchas veces antecede a los casos de femicidio y cómo muchas veces el gran número de casos de femicidio que se registra sucede en el ámbito privado. (p.2)

En lo que respecta a Ecuador, a lo largo de nuestra historia, el asesinato de mujeres siempre ha existido, pero ha sido invisibilizado por la falta de conocimiento y por poca difusión del tema. Al respecto, Pozo Enríquez (2019) indica que:

En Ecuador, se puede identificar que el femicidio constituye un concepto aún en proceso de construcción, al ser relativamente nueva su aparición y manejo en el ámbito jurídico nacional no cuenta con un claro sistema de diferenciación frente a las muertes de mujeres causadas sin motivación de género, pues existen muertes que pese a ser identificadas como violentas o pese a haber sido perpetradas por hombres, no registran precedentes de dominación o patrones de discriminación. (p.19) 
El asesinato es solo el abuso extremo de las mujeres por parte de los hombres, y está relacionado con las costumbres y tradiciones sociales de aceptar el abuso de las mujeres y a su vez que ellas lo miren con algo que está bien y correcto no ha sido lo suficientemente discutido, en este sentido Carrillo Kennedy (2018) afirma:

Es importante mencionar que el estudio del femicidio en el Ecuador, publicado por la Comisión de Transición de las Mujeres y la Igualdad de Género, señala que las vio ᄀlencias en contra de las mujeres no son hechos fortuitos y aislados sino prácticas generalizadas y sistemáticas llevadas a cabo por los varones para controlar, intimidar y subordinar a las mujeres. (p.128)

El tema del femicidio en el Ecuador ha ido tomando forma con la aprobación del Código Orgánico Integral Penal, ya que debido a cuestiones culturales y sociológicas arraigadas dentro del país, en donde se calificaba al asesinato de las mujeres en el seno familiar como crímenes familiares, y siempre se buscaba imponer la culpa sobre la víctima, justificando al agresor, a esto se le suman muchas variantes, ya que el hecho de que muchas mujeres decidieran continuar casadas o conviviendo con su agresor, lo hacían debido a la gran presión social que se ejercía sobre ellas, ya que se les consideraba como indignas, y motivo de vergüenza familiar, una frase que justificaba a los agresores y que lamentablemente formaba parte de la cultura de los ecuatorianos era el dicho de "aunque te pegue o te mate, tu esposo es". Poco a poco las mujeres fueron obteniendo la protección estatal que tanto requerían, así fue como surgieron las primeras comisarías de la mujer.

De allí que el Estado Ecuatoriano mediante la elaboración de las leyes y redacción de código busca proteger a la mujer y definir los hechos que vulneran su seguridad, en el siguiente cuadro se puede observar algunas de las normas vigentes: 


\section{Cuadro 1.}

Normativa Legal.

\begin{tabular}{|c|c|}
\hline Normas & Contenido \\
\hline $\begin{array}{l}\text { Ley Orgánica Integral para Prevenir y } \\
\text { Erradicar la Violencia Contra las } \\
\text { Mujeres (2018) }\end{array}$ & $\begin{array}{l}\text { Artículo 4.- Definiciones. Para efectos de } \\
\text { aplicación de la presente Ley, a } \\
\text { continuación, se definen los siguientes } \\
\text { términos: } \\
\text { 1.Violencia de género contra las mujeres. } \\
\text { - Cualquier acción o conducta basada en } \\
\text { su género que cause o no muerte, daño } \\
\text { y/o sufrimiento físico, sexual, psicológico, } \\
\text { económico o patrimonial, gineco- } \\
\text { obstétrico a las mujeres, tanto en el } \\
\text { ámbito público como privado. } \\
\text { 2. Daño. - Es el perjuicio causado a una } \\
\text { persona como consecuencia de un } \\
\text { evento determinado. En este caso el daño } \\
\text { implica la lesión, menoscabo, mengua, } \\
\text { agravio, de un derecho de la víctima. } \\
\text { 3. Estereotipos de género. - Es toda } \\
\text { preconcepción de atributos } \\
\text { características poseídas o papeles que } \\
\text { son o deberían ser ejecutados por } \\
\text { hombres y mujeres, respectivamente. } \\
\text { 4. Víctimas. - Se considera a la mujer y/o } \\
\text { demás miembros integrantes del núcleo } \\
\text { familiar que sufran violencia o afectación } \\
\text { ejecutada por un miembro de la familia. } \\
\text { 5. Persona agresora. - Quien comete una } \\
\text { acción u omisión que implique cualquier } \\
\text { forma de violencia contra las mujeres. } \\
\text { 6. Ámbito público. - Espacio en el que se } \\
\text { desarrollan las tareas políticas, } \\
\text { productivas de la sociedad y de servicios } \\
\text { remunerados, vinculadas a la gestión de } \\
\text { lo público. } \\
\text { 7. Ámbito privado. - Espacio en el que se } \\
\text { desarrollan las tareas reproductivas; de la } \\
\text { economía del cuidado, remuneradas o } \\
\text { no, vinculadas a la familia y a lo } \\
\text { doméstico. } \\
\text { 8. Relaciones de poder. - Acciones, } \\
\text { omisiones y prácticas sociales, políticas, } \\
\text { económicas, culturales o simbólicas que } \\
\text { determinan la imposición de la voluntad } \\
\text { de una persona o arupo por sobre la de }\end{array}$ \\
\hline
\end{tabular}




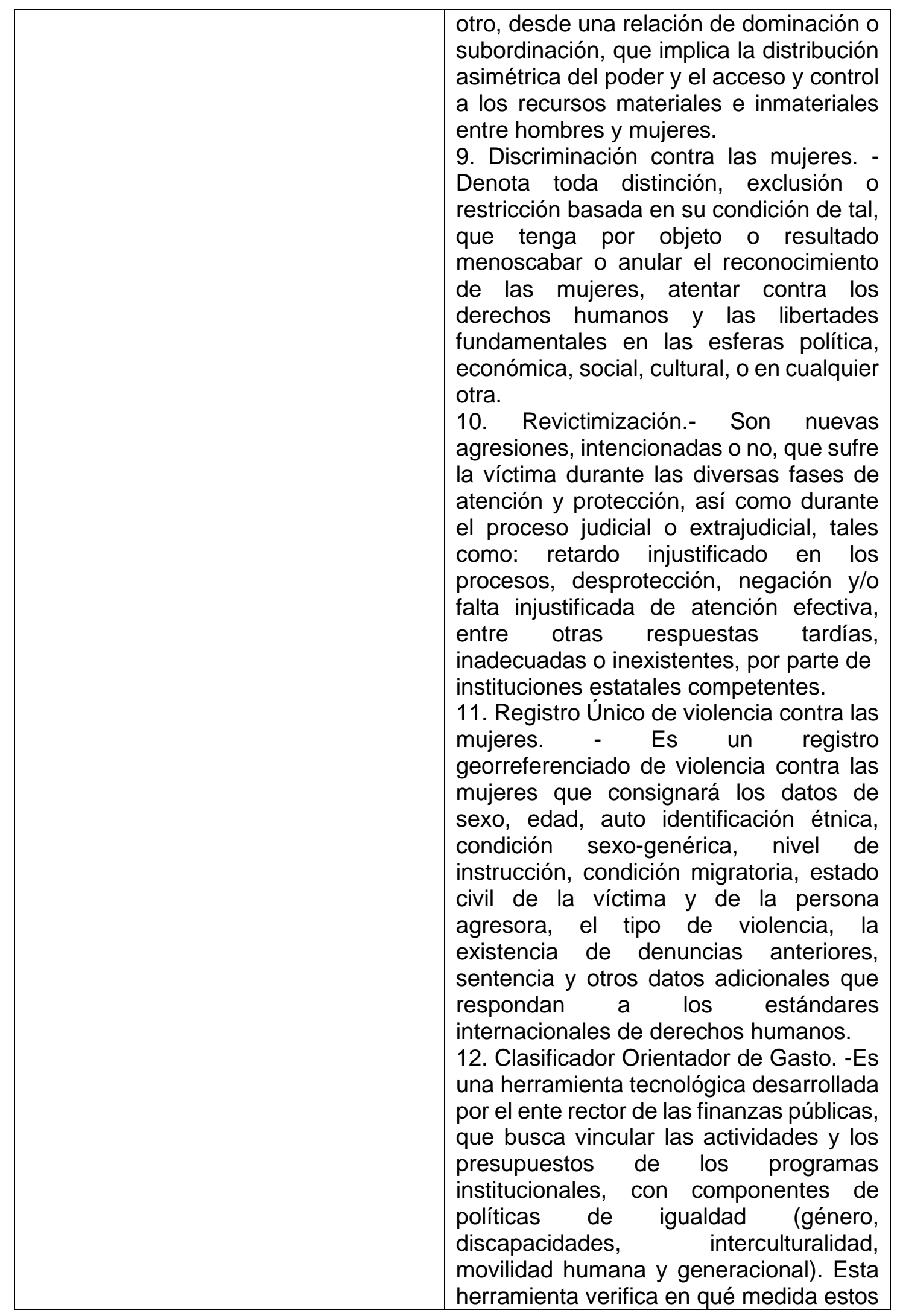




\begin{tabular}{|c|c|}
\hline & $\begin{array}{l}\text { componentes están siendo incorporados } \\
\text { en el presupuesto de las instituciones } \\
\text { públicas y facilita el seguimiento de la } \\
\text { ejecución presupuestaria por cada } \\
\text { entidad. } \\
\text { 13. Masculinidades. - Es la construcción } \\
\text { sociocultural sobre roles y valores } \\
\text { asociados al comportamiento de los } \\
\text { hombres. Se aboga por que se ejerzan } \\
\text { sin machismo ni supremacía o violencia } \\
\text { hacia las mujeres.. }\end{array}$ \\
\hline Código Orgánico Integral Penal (2014) & $\begin{array}{l}\text { Artículo 140.- Asesinato. - La persona que } \\
\text { mate a otra será sancionada con pena } \\
\text { privativa de libertad de veintidós a } \\
\text { veintiséis años, si concurre alguna de las } \\
\text { siguientes circunstancias: } \\
\text { 1. A sabiendas, la persona infractora ha } \\
\text { dado muerte a su ascendiente, } \\
\text { descendiente, cónyuge, conviviente, } \\
\text { hermana o hermano. } \\
\text { 2. Colocar a la víctima en situación de } \\
\text { indefensión, inferioridad o aprovecharse } \\
\text { de esta situación. } \\
\text { 3. Por medio de inundación, } \\
\text { envenenamiento, incendio o cualquier } \\
\text { otro medio se pone en peligro la vida o la } \\
\text { salud de otras personas. } \\
\text { 4. Buscar con dicho propósito, la noche o } \\
\text { el despoblado. } 5 \text {. Utilizar medio o medios } \\
\text { capaces de causar grandes estragos. } \\
\text { 6. Aumentar deliberada } \\
\text { inhumanamente el dolor a la víctima. } \\
\text { 7. Preparar, facilitar, consumar u ocultar } \\
\text { otra infracción. } \\
\text { 8. Asegurar los resultados o impunidad de } \\
\text { otra infracción. } \\
\text { 9. Si la muerte se produce durante } \\
\text { concentraciones masivas, tumulto, } \\
\text { conmoción popular, evento deportivo o } \\
\text { calamidad pública. } \\
\text { 10. Perpetrar el acto en contra de una o } \\
\text { un dignatario o candidato a elección } \\
\text { popular, elementos de las Fuerzas } \\
\text { Armadas o la Policía Nacional, fiscales, } \\
\text { jueces o miembros de la Función Judicial } \\
\text { por asuntos relacionados con sus } \\
\text { funciones o testigo protegido. }\end{array}$ \\
\hline
\end{tabular}




\begin{tabular}{|l|l|}
\hline Artículo 144.- Homicidio. - La persona que \\
mate a otra será sancionada con pena \\
privativa de libertad de diez a trece años. \\
Artículo 145.- Homicidio culposo. - La \\
persona que, por culpa mate a otra, será \\
sancionada con pena privativa de libertad \\
de tres a cinco años.
\end{tabular}

Elaboración: Los autores.

Promover la lucha en contra de la violencia es una respuesta a los fenómenos sociales que se desarrollan dentro de la sociedad en la que vivimos, y los cuales afectan principalmente a las mujeres y muchas veces la intimidación es imperceptible por la víctima, debido a que esta se encuentra normalizada.

\section{FINANCIAMIENTO}

No monetario.

\section{AGRADECIMIENTO}

A la Universidad Regional Autónoma de los Andes, Ecuador; por motivar el desarrollo de la Investigación.

\section{REFERENCIAS CONSULTADAS}

Asamblea Nacional República del Ecuador (2018). Ley para prevenir y erradicar la violencia contra las mujeres. [Law to Prevent and Eradicate Violence against Women]. Ley 0 Registro Oficial Suplemento 175 de 05-feb.-2018 Estado: Vigente. Recuperado de: https://n9.cl/h7v9h

Código Orgánico Integral Penal. (2014). [Comprehensive Criminal Organic Code] Quito. CEP.

Carrillo Kennedy, J. (2018). Incidencia de femicidio en el Ecuador y en la provincia del Guayas. [Incidence of femicide in Ecuador and the province of Guayas]. Revista Universidad y Sociedad, 10(1), 125-133. Recuperado de: https://n9.cl/hw1u2 
Corporación Promoción de la Mujer (2018) Informe sobre la situación del femicidio en Ecuador. Audiencia Temática sobre "Denuncias de Feminicidio en Ecuador" $170^{\circ}$ Período de Sesiones de la Comisión Interamericana de Derechos Humanos. [Report on the situation of femicide in Ecuador. Thematic Hearing on "Denunciations of Feminicide in Ecuador" 170th Period of Sessions of the InterAmerican Commission on Human Rights]. Recuperado de: https://n9.cl/3ozd

Goyas Cespedes, L., Zambrano Noles, S., Cabanes Espino, I (2018) Violencia contra la mujer y regulación jurídica del femicidio en Ecuador. [ Violence against women and legal regulation of femicide in Ecuador]. Revista de investigación en Derecho, Criminología y Consultoría Jurídica. 12, (23),129-15. http://dx.doi.org/10.32399/rdk.12.23.634

Pozo Enríquez, M. (2019) Análisis de la tipicidad, aplicación y sanción del delito de femicidio en Ecuador a partir del estudio de sentencias de casación emitidas por la Corte Nacional de Justicia. [ Analysis of the typicity, application and punishment of the crime of femicide in Ecuador based on the study of cassation sentences issued by the National Court of Justice]. Instituto de Altos Estudios Nacionales Universidad de Posgrado del Estado. Recuperado de: https://n9.cl/21izp

Proaño Reyes, G. (2019). Femicidio: una investigación con perspectiva de género. [ Femicide: an investigation with a gender perspective] luris Dictio, 24(24),93109. DOI: http://dx.doi.org/10.18272/iu.v24i24.1457 